\title{
Novel method for fog monitoring using cellular networks infrastructures
}

\section{N. David ${ }^{1}$, P. Alpert ${ }^{1,2}$, and H. Messer ${ }^{3}$}

${ }^{1}$ The Department of Geophysical, Atmospheric and Planetary Sciences, Tel-Aviv University, Tel Aviv, Israel

${ }^{2}$ The Porter School of Environmental Studies, Tel-Aviv University, Tel Aviv, Israel

${ }^{3}$ The School of Electrical Engineering, Tel-Aviv University, Tel Aviv, Israel

Received: 12 July 2012 - Accepted: 10 August 2012 - Published: 17 August 2012

Correspondence to: N. David (noamda@post.tau.ac.il)

Published by Copernicus Publications on behalf of the European Geosciences Union.

Novel method for fog monitoring using cellular networks infrastructures

N. David et al.

\section{Title Page}

\section{Abstract}

Conclusions

Tables

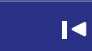

4

Back

Full Screen / Esc

Printer-friendly Version

Interactive Discussion 


\section{Abstract}

A major detrimental effect of fog is visibility limitation which can result in serious transportation accidents, traffic delays and therefore economic damage. Existing monitoring techniques including satellites, transmissometers and human observers - suffer from 5 low spatial resolution, high cost or lack of precision when measuring near ground level. Here we show a novel technique for fog monitoring using wireless communication systems. Communication networks widely deploy commercial microwave links across the terrain at ground level. Operating at frequencies of tens of $\mathrm{GHz}$ they are affected by fog and are, effectively, an existing, spatially world-wide distributed sensor network that can provide crucial information about fog concentration and visibility. Fog monitoring potential is demonstrated for a heavy fog event that took place in Israel. The correlation between transmissomters and human eye observations to the visibility estimates from the nearby microwave links was found to be 0.53 and 0.61 , respectively. These values indicate the high potential of the proposed method.

\section{Introduction}

Fog is defined as water droplets suspended in the atmosphere, near the surface of earth that reduce visibility to less than $1 \mathrm{~km}$ (AMS, 2000). The impact of fog on human beings and on the environment is considerable. Fog harvesting, for instance, can produce fresh water for gardening, afforestation and even potable water that may have

20 a significant contribution particularly in water scarce regions (Oliver, 2004; Klemm et al., 2012). Moreover, in forest ecosystems, fog takes a cardinal part in the water balance of these natural environments (e.g. Dawson, 1998; Wrzesinsky and Klemm, 2000). On the other hand, air pollutants that exist in the atmosphere can interact and dissolve in the condensed water droplets creating smog (a portmanteau of smoke and fog) that may harm human health, adversely affect plants and damage structures (e.g. Wichmann et al., 1989; An et al., 2008). Information concerning the Liquid Water

\section{Novel method for fog monitoring using cellular networks infrastructures}

N. David et al.

\section{Title Page}


Content (LWC) of fog makes it possible to define the concentration of air pollutants through analysis of fog droplet samples (e.g. Tago et al., 2006). However, the central negative effect attributed to fog, is reduced visibility that can lead to heavy financial damages, grave accidents and loss of life (Croft et al., 1995; Pagowski et al., 2004). The 5 total economic impact of the presence of fog on aviation, marine and land transportation can reasonably be compared to the impact of tornadoes or, in some cases, even those of hurricanes (Gultepe et al., 2007). Furthermore, it has been recently shown that while the number of road accidents due to rain has declined considerably, the totals in foggy conditions have not changed significantly (Pisano et al., 2008).

10 Despite the importance of fog observation, current monitoring instruments are often insufficient (e.g. Pagowski et al., 2004), as they are not wide spread, costly to implement and require special installation procedures. Predominant techniques for detection of fog and measuring visibility include: trained human observers, transmissometers, satellites and instruments that measure the scatter coefficient. A trained human 15 observer assesses visibility by the appearance or occlusion of objects at known distances from the observer's present location. However, this assessment is a subjective judgment by a particular observer, one observer's estimation might disagree with another's when assessing the same visibility conditions. One of the most common instruments for measuring the light extinction coefficient is the transmissometer (WMO, 2008). This instrument measures the mean light extinction coefficient in a horizontal cylinder of air between a transmitter and a receiver that can be located from a few meters to several hundreds of meters apart. The transmitter emits a modulated flux of light with constant mean power. The receiving unit contains a photodetector to measure the light falling on it. Although this device is considered very accurate, its costs are extremely high. An additional technique includes instruments measuring the scatter coefficient. Both scattering and absorption contribute to the atmospheric attenuation of light. The main contributor to reduced visibility is the scatter phenomena created by the water droplets, while the absorption factor is, in general, negligible. This being the case, measuring the scatter coefficient may be considered as equal to measuring the

\section{AMTD}

$5,5725-5752,2012$

\section{Novel method for fog monitoring using cellular networks infrastructures}

N. David et al.

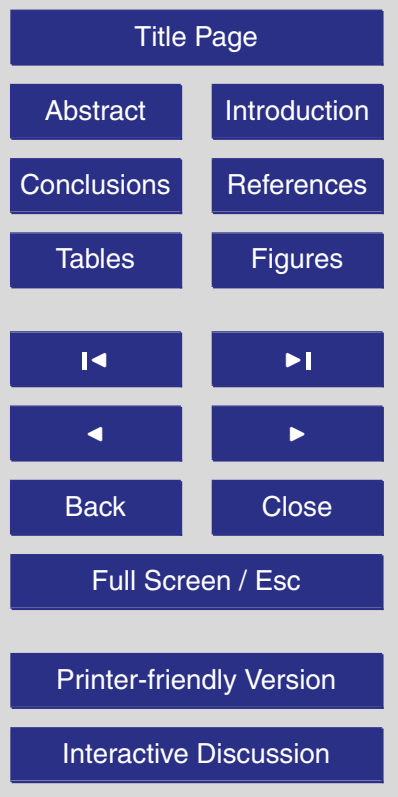


extinction coefficient. By concentrating a beam of light on a small volume of air, the proportion of light being scattered in sufficiently large angles and in non-critical directions can be determined through photometric means (WMO, 2008). However, this technique only allows for a small sample volume to be measured. As a result, the 5 visibility representativeness obtained is poor. Satellites have the advantage of providing large spatial coverage. Nevertheless, in some cases, they struggle to supply fog detections at ground level. High or middle altitude clouds along the line of sight between the ground and the system may obscure ground level fog. It is also difficult to differentiate, using this technique, whether the observation reflects actual fog, or low 10 stratus clouds, found at higher levels off the surface. In order to improve the fog detection algorithms additional spectral channels are needed (Ellrod and Gultepe, 2007). Some instruments were designed to provide measurements of the fog LWC (Gerber, 1984; Arends et al., 1992; Emert, 2001; Schwarzenboeck et al., 2009). While all are spatially limited, commonly used tools include the Particle Volume Monitor (PVM), For15 ward Scattering Spectrometer Probe (FSSP) and hot-wire probes. The PVM is based on the principle of forward scattering of light and supplies information concerning the LWC and total particle surface area. The FSSP is designed to provide measurements of the droplet size distribution and based on this information the LWC can be derived. Hot-wire probes, mostly used on aircrafts, measure LWC by monitoring the energy required to evaporate collected fog-droplets using inertial impaction and interception on a heated cylinder.

At frequencies of tens of $\mathrm{GHz}$, various atmospheric hydrometeors: precipitation, water vapor, sleet, mist and fog affect microwave beams, causing perturbations to radio signals (Rec. ITU-R P.838-2, 2004; Rec. ITU-R P.676-6, 2005; Rec. ITU-R P.840-4, 2009). Thus, wireless communication networks can be considered to be built in environmental monitoring facilities, as was first demonstrated for rainfall observations by Messer et al. (2006). Typically, the Microwave Links (MLs) utilized in these networks are installed at heights of a few tens of meters off the surface, they are widely spread across the terrain and provide continuous measurements at high temporal resolution.

\section{Novel method for fog monitoring using cellular networks infrastructures}

N. David et al.

\section{Title Page}

Full Screen / Esc

Printer-friendly Version

Interactive Discussion

\section{8}


Finally, the implementation costs are minimal since the requested data are standard data collected and logged routinely by the communication providers. However, most of the work done in this field of research till today was focused on the ability to monitor rainfall (e.g. Leijnse, 2007; Goldshtein et al., 2009; Zinevich et al., 2008, 2009, 5 2010; Rayitsfeld et al., 2011). In this paper we present a novel method for fog monitoring based on existing Received Signal Level (RSL) measurements taken by a cellular communication network.

\section{Methodology}

Fog is one of the several atmospheric phenomena that affect MLs, causing an addi10 tional signal loss to the microwave electromagnetic beams with respect to that created during non-foggy periods.

Two fundamental stages in fog monitoring using measurements from wireless communications networks are distinguished here: identification of the fog phenomenon using additional side information as reference data, and the estimation of its degree.

15 As our primary aim is to prove the feasibility of our proposed methodology, the technique was restricted to situations where other hydrometeors (rainfall, sleet, snow) were nonexistent along the propagation path.

\subsection{Fog identification}

The goal of this stage is to allow for the identification of fog, and distinguishing the existence of this phenomenon from situations when it is not present using additional standard meteorological instruments (temperature, humidity and rain gauges).

A simplified model describing the attenuation of the microwave wireless signal, $\gamma$, as a result of the different atmospheric hydrometeors, can be described as follows (Zinevich et al., 2010):

$25 \gamma=A_{\mathrm{p}}+A_{\mathrm{v}}+A_{\mathrm{f}}+A_{\mathrm{w}}+q_{\mathrm{n}}+$ noise $\left(\mathrm{dB} \mathrm{km}^{-1}\right)$
AMTD

$5,5725-5752,2012$

\section{Novel method for fog monitoring using cellular networks infrastructures}

N. David et al.

\section{Title Page}

Abstract Introduction

Conclusions References

Tables Figures

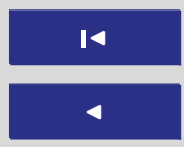
$>$ I

Back Close Full Screen / Esc

Printer-friendly Version

Interactive Discussion 
where:

$A_{\mathrm{p}}$ - attenuation as a result of other-than-fog precipitation (rain, sleet, snow)

$A_{\mathrm{v}}$ - water vapor attenuation

$A_{\mathrm{f}}-$ fog induced attenuation

$5 \quad A_{\mathrm{w}}$ - wet antenna attenuation

$q_{\mathrm{n}}$ - system quantization noise

Noise-All other signal perturbations, e.g. which created as a result of scintillation effects, ducting or winds that may oscillate the microwave units (Leijnse, 2007).

In this study we assume that $A_{p}=0$. This assumption is validated using nearby standard measurements of rain gauges and temperature meters (Fig. 1b).

In a typical cellular backhaul network, microwave links at different lengths and direction exist at an area of a size similar to a typical fog filed, e.g. of the order of several $\mathrm{km}^{2}$ (Pagowski et al., 2004). The availability of diverse RSL measurements enables us to identify the $A_{\mathrm{w}}$ component. Because of the high level of humidity during fog, a thin layer 15 of water may accumulate on the outside covers of the microwave antenna and may create additional attenuation to the received signal, beyond that caused by the fog in the atmospheric path. In order to estimate the amount of this attenuation, $A_{w}$, and if it did in fact occur, we make use of measurements over particularly short MLs (preferably of up to a few hundreds of meters long) that are located near longer links, since the effect of fog, even a heavy one, as well as of water vapor on the signal attenuation at such short ranges is much smaller comparing to the attenuation created in longer MLs of several km in lengths (Rec. ITU-R P.676-6, 2005; Rec. ITU-R P.840-4., 2009). This being the case, any additional attenuation, if detected, can be directly attributed to the layer of water on the antennas, its value measured, and that value can be used to adjust the measurements on the longer links.

In order to identify the specific attenuation created as a result of the fog itself, we set a baseline, zero RSL value separately for each link. Since the density of water vapor in the atmosphere affects MLs (Rec. ITU-R P.676-6, 2005; David et al., 2009, 2011) and since humidity is particularly high during fog, the zero level is chosen by selecting the

\section{Novel method for fog monitoring using cellular networks infrastructures}

N. David et al.

\section{Title Page}

Abstract Introduction

Conclusions

Tables

References

Figures

14

4

Back

Full Screen / Esc

Printer-friendly Version

Interactive Discussion
$>1$

$>$

Close 
median value from RSL measurements taken over a period of several hours, during which the relative humidity in the area, as measured by the meteorological stations at the site, is around $90 \%$. By this selection of the base line, the water vapor effect, $A_{v}$, is minimized and is assumed to be zero.

5 Thus, fog is identified as being present when the measured RSL value crosses the predefined threshold during times of high relative humidity (of the order of $90 \%$ and more), while the additional attenuation is observed simultaneously by the numerous areal MLs.

\subsection{Visibility estimation}

10 After detection of the existence of fog, the average amount of LWC per unit of volume in the fog was calculated, from which the range of visibility was estimated.

\subsubsection{Liquid water content estimation}

The relation between the fog induced attenuation and the total water content per unit volume is given by ITU-R (P.840-4):

$15 \quad A=\Phi \cdot \operatorname{LWC}\left(\mathrm{dB} \mathrm{km}^{-1}\right)$

where $A$ is the attenuation of the microwave signal in $\left(\mathrm{dB} \mathrm{km}^{-1}\right), \Phi$ is a frequency and temperature dependent coefficient, and LWC is the liquid water content $\left(\mathrm{g} \mathrm{m}^{-3}\right)$. A mathematical model based on Rayleigh approximation (fog drops are generally less than $0.01 \mathrm{~cm}$, small with respect to centimeter microwaves) is used for the calculation 20 of $\Phi$, for frequencies of up to $200 \mathrm{GHz}$ (ITU-R P.840-4, 2009):

$\Phi=\frac{0.819 f}{\mathcal{E}^{\prime \prime}\left(1+\beta^{2}\right)} \quad\left(\mathrm{dB} \mathrm{km}^{-1}\right) /\left(\mathrm{gm}^{-3}\right)$

with $f$ being the link frequency $(\mathrm{GHz})$, while:

$\beta=\frac{2+\varepsilon^{\prime}}{\varepsilon^{\prime \prime}}$.
AMTD

$5,5725-5752,2012$

\section{Novel method for fog monitoring using cellular networks infrastructures}

N. David et al.

\section{Title Page}

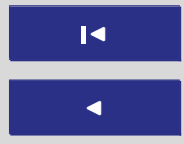

$>$ I

Back

-

\section{Full Screen / Esc}

Printer-friendly Version

Interactive Discussion 
The complete expression of the complex dielectric permittivity of water $\varepsilon(f)=\varepsilon^{\prime}(f, T)+$ $i \varepsilon^{\prime \prime}(f, T)$, is detailed in literature (Rec. ITU-R P.840-4, 2009).

Based on the RSL measurements, the fog induced attenuation $A$ can be derived. Then, given the temperature and the frequency of a $\mathrm{ML}$, the parameter $\Phi$ is calculated, 5 and finally the LWC is obtained using Eq. (2).

Note, however, that the deterministic relation (Eq. 2) can be transformed into:

$\mathrm{RSL}_{i}=f\left(\mathrm{LWC}_{i}, \underline{\boldsymbol{\theta}}_{i}\right)+$ noise; $(\mathrm{dBm})$

where $\mathrm{RSL}_{i}$ is the RSL of the $i$-th link and $\boldsymbol{\theta}_{i}$ is a vector of all the other, known parameters (temperature, frequency etc.) of the link. Given RSL measurements from $L$

10 links in a given fog field where all links see the same liquid water content, LWC can be extracted from $L$ equations as Eq. (5) by a least squares or other estimation methods with a better accuracy than in the case of a single link.

\subsubsection{Visibility calculation}

Visibility is defined as the greatest distance in a given direction at which it is possible to 15 see and identify a prominent black object against the sky at the horizon in the daylight, or the greatest distance it could be seen and recognized during night if the general illumination were raised to the level of normal daylight (WMO, 2008).

Since LWC is highly correlated to visibility, several empirical models were developed to estimate one quantity given the other (e.g. Tomasi and Tampieri, 1976; Pinnick et al., 20 1978; Kunkel, 1984; Klemm et al., 2005; Gultepe et al., 2006; Acker et al., 2010). In general, these models can be expressed as follows while $V$ signifies the visibility:

$V=\alpha \cdot \operatorname{LWC}^{-\beta} \quad(\mathrm{km})$.

The constants $\alpha$ and $\beta$ are empirical and may accept different values, using different approaches.

25 Conventionally used empirical values for $\alpha$ and $\beta$ were found based on approximately $90 \mathrm{~h}$ of fog droplet data by Kunkel (1984). This expression $(\alpha=0.027, \beta=0.88)$, which

\section{AMTD}

$5,5725-5752,2012$

\section{Novel method for fog monitoring using cellular networks infrastructures}

N. David et al.

\section{Title Page}

Abstract

Introduction

Conclusions

References

Tables

Figures

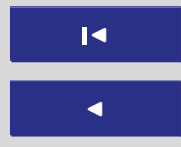

$\Delta$

Back

Close

Full Screen / Esc

Printer-friendly Version

Interactive Discussion 
is one out of two relations used in this research to estimate visibility, is commonly used for visibility estimations in many prediction models (e.g. Benjamin et al., 2004; Terradellas and Bergot, 2007).

The microphysical structure of fog, the chemical composition of the condensation 5 nuclei, surface and atmospheric mixing conditions, the size distribution of the droplets and the droplets number concentration per unit volume, all affect the visibility-LWC relation (e.g. Altshuler, 1984; Zhao and Wu, 2000; Acker et al., 2010). Thus, for a certain constant LWC level, visibility can vary (e.g. Klemm et al., 2005).

Gultepe et al. (2006) have recently shown that taking into account an additional pa10 rameter - the droplet number concentration, $N_{\mathrm{D}}$, in addition to the LWC, in the formula improves the accuracy of the visibility estimations:

$V=\frac{1.002}{\left(\mathrm{LWC} \times N_{\mathrm{D}}\right)^{0.6473}} \quad(\mathrm{~km})$.

This is the second expression used here to calculate visibility estimates.

In cases when Eq. (7) was used to estimate the visibility, the droplet number con15 centration $\left(N_{\mathrm{D}}\right)$ within the fog was derived based on the temperature measurements, $T$, using the following known relation (Gultepe and Isaac, 2004):

$N_{\mathrm{D}}=-0.071 T^{2}+2.213 T+141.56\left(\mathrm{~cm}^{-3}\right)$.

\section{Results}

Starting on the evening of 15 November 2010, heavy advection fog began developing and expanding to the north along Israel's Mediterranean coast. Fog conditions continued through the morning hours of 16 November 2010. We focus on the central western coastal region (Tel-Aviv city area) where several means for measuring the phenomenon exist. In addition to these, there are 10 commercial MLs installed over four different physical paths in the study area, as well as 10 short MLs (with lengths up to $400 \mathrm{~m}$ )

\section{Novel method for fog monitoring using cellular networks infrastructures}

N. David et al.

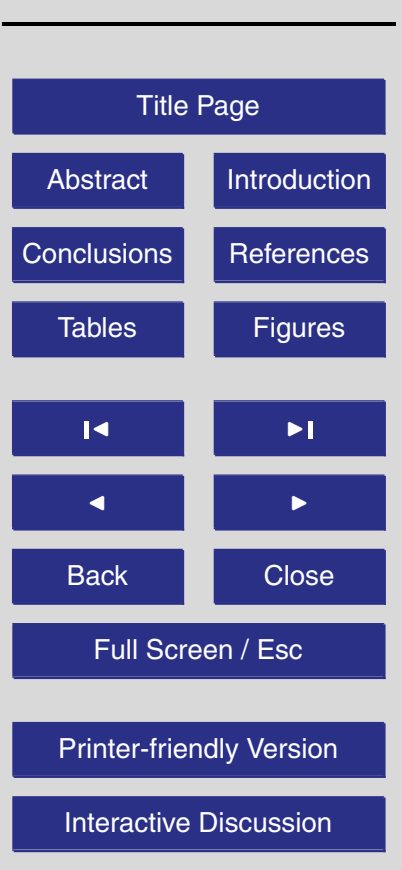




\subsection{Fog detection and visibility estimation using traditional monitoring techniques}

The satellite image shows (Fig. 1a) the wide area affected during this fog event, as well as the discussed site which is detailed in the map (Fig. 1b) adjacent to the image.

5 According to the measurements of the two ground stations in the area (Fig. 1b), the relative humidity registered between 18:00 and 08:00 UTC of the following morning varied between $88 \%$ and $99 \%$, with a temperature range of $17-24{ }^{\circ} \mathrm{C}$. No precipitation, sleet or snow were measured during this time frame.

Figure 2 illustrates one limitation of the satellite system in providing indication for the 10 fog event due to middle and high altitude cloud cover that obstructs the satellite line of sight to the ground, essentially partly hiding the ground level fog from the satellite's vantage point.

Figure 3a shows the visibility results registered by the professional human observer located at Beit Dagan surface station (Fig. 1b) who detected fog between 22:00 and 15 07:00 UTC.

The graphs described in Fig. 3b are based on Runaway Visual Range (RVR) measurements (AMS, 2000) of three transmissometers located at the Ben Gurion airport. According to these instruments, between 21:35 and 07:20 UTC of 15-16 November 2010 , at least one of the three devices detected fog.

\subsection{Fog identification utilizing MLs}

Starting from between 18:45 and 19:30 h UTC the RSL which were measured by the MLs located along L1, L2 and L4 paths (Fig. 1b) started to drop beneath the predefined reference RSL. Figure 4 presents the RSL measurements of the links between 15:00 h of 15 November to 10:00 h UTC of 16 November.

In order to test the possibility of additional attenuation that may result from a possible condensation on the antenna, we studied the RSL measurements of 10 very short links (of up to $400 \mathrm{~m}$ in length). These MLs are installed at elevations of $11-31 \mathrm{~m}$ above

\section{Novel method for fog monitoring using cellular networks infrastructures}

N. David et al.

\section{Title Page}

Abstract Introduction

Conclusions References

Tables Figures

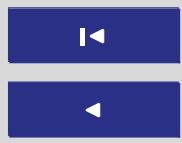
$>$ I

Back D

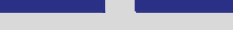

Full Screen / Esc

Printer-friendly Version

Interactive Discussion 
ground (between 4 to $30 \mathrm{~m}$ a.b.I.) and operate in frequencies of 22-23, 25-26 and 37-39 GHz. The RSLs measured between 15:00 to 10:00 of 15-16 November, respectively, fluctuated around the same constant value to within the system's quantizing error. Consequently, we assumed that in this case, even if condensation on the antenna did 5 occur, the possible resulting signal loss was lower than the system quantization error, hence no additional attenuation was taken into account as a result of this possibility.

Table 1 details the attenuation range as measured using the various MLs located along L1 to L4 propagation paths.

Fog was detected as being present between 18:45 and 05:30 UTC of the 15-16 10 November night, based on the excess attenuation measurements of the longer MLs combined with the high relative humidity measured in the area while the existence of other precipitation phenomena was ruled out.

The results presented in Table 1 point out that the signal attenuation over a constant distance is, in general, greater the higher the operating frequency of the ML. 15 This observation is expected during fog episodes as the radio beam is more strongly attenuated by the fog droplets at higher frequencies (Rec. ITU-R P.840-4, 2009). Additionally, the signal loss at a constant frequency is increased with link length which is also expected, since the wave traverses a greater span of fog.

The microwave system we used for measuring the fog provides minimum and maximum RSL data every $15 \mathrm{~min}$, of which we used the maximum measurements to produce the minimal attenuation measures. This is justified by the slow change over time of fog that was present in the area from the early night hours until the following morning, a common occurrence when heavy fog is created (e.g. Kunkel, 1984; Gultepe et al., 2006) with respect to the relatively high sampling rate of the system $-15 \mathrm{~min}$ (thus, the minimum RSL measurements actually document more instant phenomena than the maximum RSL measurements do).

\section{Novel method for fog monitoring using cellular networks infrastructures}

N. David et al.

\section{Title Page}

Abstract Introduction

Conclusions References

Tables Figures

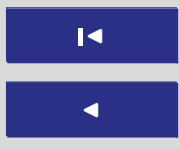

$\Delta$

Back

$\checkmark$

Close
Full Screen / Esc

Printer-friendly Version

Interactive Discussion 


\subsection{Visibility estimation using MLs}

Using the procedure described in the methodology section, LWC values were calculated for each of the links first. The attenuation measurements were attributed to fog only when these were registered by all links operating across the same atmospheric 5 path during the same $15 \mathrm{~min}$ time interval. Note that over each path there are either two or four operating links, consequently, 2-4 measurements are made for each track (every $15 \mathrm{~min}$ ). Thus, $2-4$ values of LWC exist for each path. Of these, we chose the minimal value in each case. The reasoning for this choice was based on the assumption that if slightly different values were measured, the attenuation values from which these were calculated may include other sources in addition to that caused by the fog. Thus, we chose the measurement that provided the lowest value under the assumption that it also minimized any additional interference.

The LWC values calculated varied between 0.7 and $2.8 \mathrm{grm}^{-3}$. Two specific measurements of the ML located along L1 path, representing both $15 \mathrm{~min}$ time intervals, 15 were of $2.8 \mathrm{grm}^{3}$.

Figure 5 presents the estimated visibility results derived from the LWC measurements based on the empirical relations found by Kunkel (1984) and by Gultepe et al. (2006), respectively. Each of the four graphs depicted in Fig. 5a and b presents visibility measurements over one of the four propagation paths (L1-L4).

$20 \quad$ Next, we compare the measurements which were taken by the human observer and by the transmissometers to those taken by the microwave system. The comparison was based on measurements which were acquired during a $24 \mathrm{~h}$ period between 15 to 16 November 2010 (from 10:00 to 10:00 UTC of the following day). The comparison was made while the measurements derived from all MLs were compared to those of 25 the observer and trassmisometers. The minimal visibility measurement of all MLs was chosen during each time interval when fog was observed over at least one propagation path. The once per hour observations, made by the observer, were compared to the microwave measurements while the MLs measurements taken into account where

\section{Novel method for fog monitoring using cellular networks infrastructures}

N. David et al.

\section{Title Page}

Abstract Introduction

Conclusions

Tables References Figures

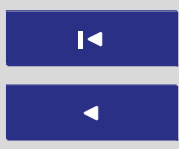
$>$ I

Back $\triangleright$ Close

\section{Full Screen / Esc}

Printer-friendly Version

Interactive Discussion 
those obtained during two $15 \mathrm{~min}$ intervals, before and right after a round hour, i.e. the minimal measurement, during the $30 \mathrm{~min}$ interval, was chosen each time. The correlation coefficient between the human eye visibility observations to those of the proposed method was found to be 0.61 based on 25 data points which were obtained using each 5 of the two techniques. An additional comparison was made while, this time, measurements derived from the three transmissometers were compared to those of the MLs. The minimal RVR measurement of all three transmissometers was chosen during each $15 \mathrm{~min}$ and then compared to the minimal visibility measurement which was acquired by all MLs during the same time frame. This being the case the correlation between 10 the observations was found to be 0.53 , based on 99 data points.

\section{Sensitivity}

The various MLs available are typified by different abilities to monitor fog based on their length, operating frequency and magnitude resolution of each specific link. The threshold LWC values that can be observed by different typical MLs are detailed in 15 Table 2.

In terms of visibility, based on the model of Gultepe et al. (2006), at $15^{\circ} \mathrm{C}$, these threshold values point out that common microwave systems have the potential to sense visibilities ranging from below $480 \mathrm{~m}$ down to below $15 \mathrm{~m}$ for LWCs of 0.02 and $4 \mathrm{grm}^{-3}$, respectively, depending on the specific properties of the ML.

\section{Uncertainties}

Some disparities between the different techniques of measuring fog are expected. These are caused due to both technical and environmental factors. The difference in location and altitude level between the measurement sites may introduce some variances due to variations in the fog concentrations and its microstructure properties with space (e.g. Pinnick et al., 1978; Kunkel, 1984). In addition, signal variations which

5737

\section{AMTD}

$5,5725-5752,2012$

\section{Novel method for fog monitoring using cellular networks infrastructures}

N. David et al.

\section{Title Page}

Abstract Introduction

Conclusions

References

Tables

Figures

14

4

Back

Full Screen / Esc

Printer-friendly Version

Interactive Discussion
$>1$

Close 
may be created as a result of scintillation or ducting may also interfere with the ability to conduct accurate measurements (Zinevich et al., 2010). Winds that may cause mechanical oscillations to the microwave units installed on the masts can also cause signal perturbations (Leijnse, 2007).

5 The predominant source of error of the LWC, as calculated here based on the ITU-R P.840-4 (2009) model, is that of the attenuation. The microwave system that was used here for the fog measurements has a quantizing error of $1 \mathrm{~dB}$ per link. As a result, there is uncertainty in the measurement of the LWC and visibility. For a given frequency, we note that the longer the link is, the error per unit of distance is smaller, and vice 10 versa. We approximated the error in measuring the LWC, and respectively the error in the resulting visibility according to the systems measuring resolution and according to each length and frequency of each ML. The error due to the measurement error of the temperature gauge (of $0.1^{\circ} \mathrm{C}$ ) is negligible with respect to the quantization error when using this model. The differences between the visibility uncertainties calculated based 15 on the two different visibility estimation models (of Kunkel, 1984 and Gultepe et al., 2006) were found to be less than $3 \mathrm{~m}$. Thus, the visibility uncertainties presented here (derived based on Eq. 6), are valid for both expressions.

The LWC and visibility are inversely related to each other (Eqs. 6 and 7). As a result, the higher the LWC measured the smaller the uncertainty in estimating the visibility, and vice versa:

$\Delta V=\frac{\alpha \beta \cdot \Delta \mathrm{LWC}}{(\mathrm{LWC})^{\beta+1}} \quad(\mathrm{~km})$.

$\triangle \mathrm{LWC}$ and $\Delta V$ are the uncertainties in measuring the LWC and visibility, respectively.

For a $1.7 \mathrm{~km}$ link operating in the $38 \mathrm{GHz}$ range (L2, L4 MLs), the error in measuring the LWC is $0.8 \mathrm{grm}^{-3}$. In this case, the error in approximating visibility is between 30 25 to $5 \mathrm{~m}$ for LWC of 0.8 and $2.4 \mathrm{grm}^{-3}$, respectively. For a link operating in the $19 \mathrm{GHz}$ range, over a distance of $8.5 \mathrm{~km}(\mathrm{~L} 1)$, the error in measuring $L W C$ was found to be $0.6 \mathrm{grm}^{-3}$. The error in visibility measurement in this case is between 35 down to $5 \mathrm{~m}$ for LWC of 0.6 and 2.4, respectively. In the case of the $4 \mathrm{MLs}$ operating along L3 5738

\section{AMTD}

$5,5725-5752,2012$

\section{Novel method for fog monitoring using cellular networks infrastructures}

N. David et al.

\section{Title Page}

Abstract Introduction

Conclusions

Tables References Figures

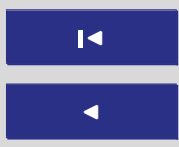

$>$ I

Back

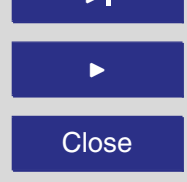

Full Screen / Esc

Printer-friendly Version

Interactive Discussion 
path, at a frequency of $18 \mathrm{GHz}$, the uncertainty in measuring the LWC is $1.2 \mathrm{grm}^{-3}$. The resulting visibility uncertainty is of 20 down to $5 \mathrm{~m}$ for LWC of 1.2 and $2.5 \mathrm{grm}^{-3}$, respectively.

Additional disparities may be introduced due to the uncertainties of the visibility esti5 mation models. Gultepe et al. (2006) have shown that the uncertainty in measuring the visibility using their improved parameterization formula (based on both LWC and $N_{\mathrm{D}}$ ) is about $29 \%$ while the Kunkel (1984) formula (developed using only the LWC) may over/underestimate the visibility in an extent that can reach $\sim 50 \%$ and more in some cases, depending on the conditions of the environment.

\section{Discussion}

The challenges in fog monitoring using commercial MLs are basically due to the fact that measurements are optimized for communication quality of service, and not for meteorological observations, so factors as the links' frequency, temporal resolution or quantization of the measurements are given. The opportunities come, on the other hand, from the availability of many links. These are widely spread across the terrain at relatively high densities and different lengths/heights, observing the atmospheric phenomenon simultaneously at various frequencies. Our results show that these systems have a potential for fog monitoring, especially in cases of heavy fog that creates severe visibility limitations particularly as it drops to the tens of meters range.

20 The links visibility estimates fit well those of other, existing techniques. The LWC within fogs typically ranges between 0.01 to $0.4 \mathrm{grm}^{-3}$ (Gultepe et al., 2007). In cases of dense fog, however, it can reach the order of $2 \mathrm{grm}^{-3}$ (Ishimaru, 1997; Zhao and Wu, 2000). Generally, the LWC measured using the proposed technique matches well the range of values reported in the literature; two specific measurements out of all reached 25 somewhat a higher value of $2.8 \mathrm{grm}^{-3}$.In addition, the MLs visibility measurements of several tens of meters were in the range of the human eye assessments which even dropped to near zero between 22:00 to 01:00 of 15-16 November. It should be noted 5739
AMTD

$5,5725-5752,2012$

\section{Novel method for fog monitoring using cellular networks infrastructures}

N. David et al.

\section{Title Page}

Abstract Introduction

Conclusions

Tables

References

Figures

14

$\rightarrow 1$

$<$

Back

Close

Printer-friendly Version

Interactive Discussion

Full Screen / Esc 
that the MLs visibility measurements should be ideally compared to the Meteorological Optical Range (MOR) measurements (WMO, 2008) derived from the transmissometers. However, these data were not available during this case and the MLs measurements were correlated with the RVR readings.

The differences between the values measured by the different methods are expected, and result from several factors as follows. The microwave system detected fog at an earlier time, i.e. starting at 18:45 to 19:30, depending on the different MLs, with respect to the transmissometers or the human observer which started measuring fog only at $21: 35$ and 22:00, respectively. The reason may be, first, that the microwave system is 10 more widely deployed across the monitored region and as a result can capture more effectively this atmospheric phenomenon. Moreover, the MLs are typically installed at a higher elevation compared to the other measurement methods. The links are installed on towers at elevations of 7-60 $\mathrm{m}$ a.g.l., while human observers and transmissometers are located closer to the ground at 10 and $2.5 \mathrm{~m}$ of elevation, respectively. It has been 15 shown that with the increase in elevation, fog concentration can significantly increase in some cases even at an order of magnitude with respect to the near-ground concentration (e.g. Pinnick et al., 1978; Kunkel, 1984). It is therefore expected, that visibility has lowered with increasing height and that fog was created at the altitude of the MLs first. Furthermore, the links are found closer to the sea-shore with respect to the locations of the other visibility measurement techniques. This sea proximity may enhance the possibility of fog creation not only because humidity is higher near sea shore, but also since salt aerosols may act as condensation nuclei to form fog droplets during times of high relative humidity (Zhuang et al., 1999). The baseline signal variations and errors (Zinevich et al., 2010) as well as the microphysical properties of fog (Zhao and Wu, 2000; Gultepe et al., 2006) may further contribute to the discrepancies.

In practice, the microwave system used here cannot detect light fogs- when the visibility is larger than the order of a few hundreds of meters due to the relatively coarse resolution of $1 \mathrm{~dB}$ per ML. Therefore, as can be seen in Fig. 5 , only when the visibility was poor enough, i.e. dropped to the order of a few tens of meters, it was observed

\section{Novel method for fog monitoring using cellular networks infrastructures}

N. David et al.

\section{Title Page}

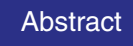


by the system. However, systems with higher measurement resolution exist, e.g. with a quantization error of $0.1 \mathrm{~dB}$ per link (Zinevich et al., 2010), and also MLs that operate at higher frequencies, e.g. around $60 \mathrm{GHz}$. It is therefore expected that using higher resolution measurement systems to monitor the phenomenon will improve the mea5 surements and the ability to track lighter fogs as described in the sensitivity section. This is particularly so when numerous MLs are used simultaneously over the same area covered by the fog.

Beyond the positive benefits of fog as illustrated in the introduction, this phenomenon poses a danger, particularly in cases of heavy fog that leads to disruptions and acci10 dents in different transportation mediums, and yet the current measurement methods are still very limited. Microwave links, forming the infrastructure of cellular communication networks, are widely deployed and exist in most places around the globe. Use of the proposed method does not require additional expenses or installation of special equipment beyond standard meteorological measurements. On the other hand, application of the proposed technique can contribute to the better understanding of fog related processes, as well as to the development of parameterizations for numerical weather prediction models. Furthermore, the potential of the system for monitoring the phenomenon and providing real time warning of it is great.

Acknowledgements. The authors are grateful to Y. Dagan, Y. Eisenberg (Cellcom), A. Shilo 20 the Israel Meteorological Service (IMS) and Meteotech for meteorological data. In addition, we would like to acknowledge and thank our current and former research team members (Tel Aviv University): A. Rayitsfeld, A. Zinevich, U. Hadar, Y. Ostromtzky, R. Samuels, D. Charkasky, O. Auslender, R. Radian for their advice and assistance throughout the research. We also wish 25 to thank EUMETSAT for satellite data. This research was supported by the Israel Science Foundation (grant No. 173/08) and also by Grant No. 2010342 from the United States - Israel Binational Science Foundation (BSF).

\section{Novel method for fog monitoring using cellular networks infrastructures}

N. David et al.

\section{Title Page}

Abstract Introduction

Conclusions

Tables References Figures
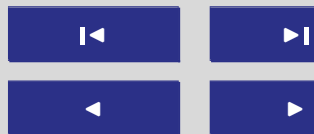

Back

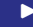

Full Screen / Esc

Printer-friendly Version

Interactive Discussion 


\section{References}

Acker, K., Wieprecht, W., Kalass, D., Möller, D., and Chaloupecky, P.: Relationship between liquid water content and visibility in low clouds occurred at Mt. Brocken, International Aerosol Conference (IAC), Helsinki, Finland, 29 August-3 September 2010.

5 Altshuler, E. E.: A simple expression for estimating attenuation by fog at millimeter wavelengths, IEEE Trans. Antennas Propag., 32, 757-758, 1984.

American Meteorological Society - AMS: Glossary of Meteorology, 2nd Edn., Allen Press, Cambridge, Massachusetts, USA, 2000.

An, D. D., Co, H. X., and Oanh, N. T. K.: Photochemical smog introduction and episode selection for the ground-level ozone in Hanoi, Vietnam, VNU J. Sci. Earth Sci., 24, 169-175, 2008.

Arends, B. G., Kos, G. P. A., Wobrock, W., Schell, D., Noone, K. J., Fuzzi, S., and Pahl, S.: Comparison of techniques for measurements of fog liquid water content, Tellus B, 44, 604611, 1992.

Benjamin, S. G., Devenyi, D., Weygandt, S. S., Brundage, K. J., Brown, J. M., Grell, G. A.,

15 Kim, D., Schwartz, B. E., Smirnova, T. G., Smith, T. L., and Manikin, G. S.: An hourly assimilation-forecast cycle: the RUC, Mon. Weather Rev., 132, 495-518, 2004.

Croft, P. J., Darbe, D., and Garmon, J.: Forecasting significant fog in Southern Alabama, Natl. Wea. Dig., 19, 10-16, 1995.

David, N., Alpert, P., and Messer, H.: Technical Note: Novel method for water vapour monitoring using wireless communication networks measurements, Atmos. Chem. Phys., 9, 2413-2418, doi:10.5194/acp-9-2413-2009, 2009.

David, N., Alpert, P., and Messer, H.: Humidity measurements using commercial microwave links, Advanced Trends in Wireless Communications, InTech publications, Croatia, 65-78, 2011.

Dawson, T. E.: Fog in the California redwood forest: ecosystem inputs and use by plants, Oecologia, 117, 476-485, 1998.

Ellrod, G. P. and Gultepe, I.: Inferring low cloud base heights at night for aviation using satellite infrared and surface temperature data, Pure Appl. Geophys., 164, 1193-1205, 2007.

Emert, S. E.: Design, construction and evaluation of the CSU optical fog detector, M.Sc. thesis, Colorado State University, Fort Collins, Colorado, 2001.

Gerber, H.: Liquid water content of fogs and hazes from visible light scattering, J. Clim. Appl. Meteorol., 23, 1247-1252, 1984.

\section{Novel method for fog monitoring using cellular networks infrastructures}

N. David et al.

\section{Title Page}

Abstract 
Goldshtein, O., Messer, H., and Zinevich, A.: Rain rate estimation using measurements from commercial telecommunications links, IEEE Trans. Signal Process., 57, 1616-1625, 2009.

Gultepe, I. and Isaac, G. A.: Aircraft observations of cloud droplet number concentration: implications for climate studies, Q. J. Roy. Meteorol. Soc., 130, 2377-2390, 2004.

5 Gultepe, I., Müller, M. D., and Boybeyi, Z.: A new visibility parameterization for warm-fog applications in numerical weather prediction models, J. Appl. Meteorol. Clim., 45, 1469-1480, 2006.

Gultepe, I., Tardif, R., Michaelides, S. C., Cermak, J., Bott, A., Bendix, J., Muller, M. D., Pagowski, M., Hansen, B., Ellord, G., Jacobs, W., Toth, G., and Cober, S. G.: Fog research: a review of past achievements and future perspectives, Pure Appl. Geophys., 164, 11211159, 2007.

Ishimaru, A.: Wave Propagation and Scattering in Random Media, IEEE Press, New York, 1997.

Klemm, O., Wrzesinsky, T., and Scheer, C.: Fog water flux at a canopy top: direct measurement 15 versus one-dimensional model, Atmos. Environ., 39, 5375-5386, 2005.

Klemm, O., Schemenauer, R. S., Lummerich, A., Cereceda, P., Marzol, V., Corell, D., Van Heerden, J., Reinhard, D., Gherezghiher, T., Olivier, J., Osses, P., Sarsour, J., Frost, E., Estrela, M. J., Valiente, J. A., and Fessehaye, G. M.: Fog as a fresh-water resource: overview and perspectives, Ambio, 41, 221-234, 2012.

20 Kunkel, B.: Parameterization of droplet terminal velocity and extinction coefficient in fog models, J. Appl. Meteorol. Clim., 23, 34-41, 1984.

Leijnse, H.: Hydrometeorological application of a microwave links: measurement of evaporation and precipitation, Ph. D. thesis, Wageningen University, The Netherlands, 2007.

Messer, $\mathrm{H}$., Zinevich, A., and Alpert, P.: Environmental monitoring by wireless communication networks, Science, 312, 713, 2006.

Oliver, J.: Fog harvesting: an alternative source of water supply on the west coast of South Africa, GeoJournal, 61, 203-214, 2004.

Pagowski, M., Gultepe, I., and King, P.: Analysis and modeling of an extremely dense fog event in Southern Ontario, J. Appl. Meteorol., 43, 3-16, 2004.

so Pinnick, R. G., Hoihjelle, D. L., Fernandez, G., Stenmark, E. B., Lindberg, J. D., and Hoidale, G. B.: Vertical structure in atmospheric fog and haze and its effects on visible and infrared extinction, J. Atmos. Sci., 35, 2020-2032, 1978.

\section{AMTD}

$5,5725-5752,2012$

\section{Novel method for fog monitoring using cellular networks infrastructures}

N. David et al.

\section{Title Page}

Abstract

Introduction

Conclusions

References

Tables

Figures

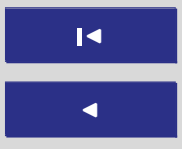

$>1$

Back

Close

Full Screen / Esc

Printer-friendly Version

Interactive Discussion 
Pisano, P. A., Goodwin, L. C., and Rossetti, M. A.: US highway crashes in adverse road weather conditions, Proceedings of the 88th Annual American Meteorological Society meeting, New Orleans, L.A., USA, 20-24 January, 1-15, 2008.

Rayitsfeld, A., Samuels, R. Zinevich, A., Hadar, U., and Alpert, P.: Comparison of two method5 ologies for long term rainfall monitoring using a commercial microwave communication system, Atmos. Res., 104-105, 119-127, 2011.

Rec. ITU-R P.838-2 - International Telecommunication Union Radiocommunication Bureau Propagation Recommendation: Specific attenuation model for rain for use in prediction methods, 2004.

10 Rec. ITU-R P.676-6 - International Telecommunication Union Radiocommunication Bureau Propagation Recommendation: Attenuation by atmospheric gases, 2005.

Rec. ITU-R P.840-4 - International Telecommunication Union Radiocommunication Bureau Propagation Recommendation: Attenuation due to clouds and fog, 2009.

Schwarzenboeck, A., Mioche, G., Armetta, A., Herber, A., and Gayet, J.-F.: Response of the 15 Nevzorov hot wire probe in clouds dominated by droplet conditions in the drizzle size range, Atmos. Meas. Tech., 2, 779-788, doi:10.5194/amt-2-779-2009, 2009.

Tago, H., Kimura, H., Kozawa, K., and Fujie, K.: Long-term observation of fogwater composition at two mountainous sites in Gunma Prefecture, Japan, Water Air Soil Poll., 175, 375-391, 2006.

20 Terradellas, E. and Bergot, T.: Comparison between two single-column models designed for short-term fog and low-clouds forecasting, Física Tierra, 19, 189-203, 2007.

Tomasi, C. and Tampieri, F.: Features of the proportionality coefficient in the relationship between visibility and liquid water content in haze and fog, Atmosphere, 14, 61-76, 1976.

Wichmann, H. E., Mueller, W., Allhoff, P., Beckmann, M., Bocter, N., Csicsaky, M. J., Jung, M., Molik, B., and Schoeneberg, G.: Health effects during a smog episode in West Germany in 1985, Environ. Health Perspect., 79, 89-99, 1989.

World Meteorological Organization - WMO: Guide to meteorological instruments and methods of observation, 7th Edn., ISBN 978-92-63-10008-5, 2008.

Wrzesinsky, T. and Klemm, O.: Summertime fog chemistry at a mountainous site in Central $30 \quad$ Europe, Atmos. Environ., 34, 1487-1496, 2000.

Zhao, Z. W. and Wu, Z. S.: Millimeter-wave attenuation due to fog and clouds, Int. J. Infrared Milli., 21, 1607-1615, 2000.
AMTD

$5,5725-5752,2012$

\section{Novel method for fog monitoring using cellular networks infrastructures}

N. David et al.

\section{Title Page}

Abstract

Introduction

Conclusions

References

Tables

Figures

14

4

Back

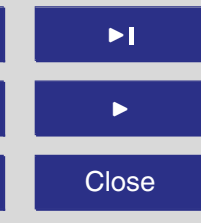

Full Screen / Esc

Printer-friendly Version

Interactive Discussion 
Zhuang, H., Chan, C. K., Fang, M., and Wexler, A. S.: Formation of nitrate and non-sea-salt sulfate on coarse particles, Atmos. Environ., 33, 4223-4233, 1999.

Zinevich, A., Alpert, P., and Messer, H.: Estimation of rainfall fields using commercial microwave communication networks of variable density, Adv. Water Resour., 31, 1470-1480, 2008.

5 Zinevich, A., Messer, H., and Alpert, P.: Frontal rainfall observation by a commercial microwave communication network, J. Appl. Meteorol. Clim., 48, 1317-1334, 2009.

Zinevich, A., Messer, H., and Alpert, P.: Prediction of rainfall intensity measurement errors using commercial microwave communication links, Atmos. Meas. Tech., 3, 1385-1402, doi:10.5194/amt-3-1385-2010, 2010.

\section{AMTD}

5, 5725-5752, 2012

\section{Novel method for fog monitoring using cellular networks infrastructures}

N. David et al.

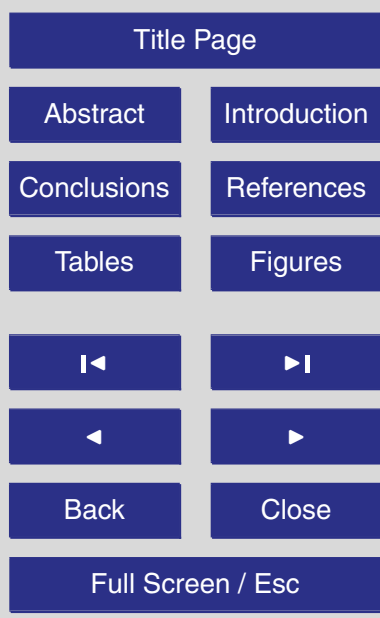

Printer-friendly Version

Interactive Discussion 


\section{AMTD}

$5,5725-5752,2012$

\section{Novel method for fog monitoring using cellular networks infrastructures}

Table 1. The fog induced attenuation measured by the 10 longer MLs located in the study area. The hours presented in this table denote the time of first detection of fog along each path.

\begin{tabular}{llcccll}
\hline $\begin{array}{l}\text { Propagation } \\
\text { path }\end{array}$ & $\begin{array}{l}\text { Fog detection } \\
\text { hour }(\mathrm{UTC})\end{array}$ & $\begin{array}{c}\text { Number } \\
\text { of MLs }\end{array}$ & $\begin{array}{c}\text { Length } \\
(\mathrm{km})\end{array}$ & $\begin{array}{c}\text { Frequency } \\
\text { range }(\mathrm{GHz})\end{array}$ & $\begin{array}{l}\text { Attenuation } \\
(\mathrm{dB})\end{array}$ & $\begin{array}{l}\text { Average attenuation } \\
\text { per km }\left(\mathrm{dBkm}^{-1}\right)\end{array}$ \\
\hline L1 & $19: 30$ & 2 & 8.5 & $18-19$ & $1-4$ & $0.1-0.5$ \\
L2 & $18: 45$ & 2 & 1.7 & $38-39$ & $1-3$ & $0.6-1.8$ \\
L3 & $01: 30$ & 4 & 4.7 & $19-20$ & 1 & 0.2 \\
L4 & $19: 00$ & 2 & 1.7 & $38-39$ & $1-3$ & $0.6-1.8$ \\
\hline
\end{tabular}

N. David et al.

\section{Title Page}

Abstract

Introduction

Conclusions

References

Tables

Figures

14

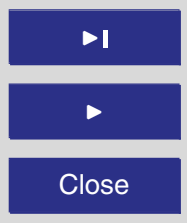

Back

Close

Full Screen / Esc

Printer-friendly Version

Interactive Discussion 


\section{AMTD}

$5,5725-5752,2012$

\section{Novel method for fog monitoring using cellular networks infrastructures}

Table 2. The minimal values of LWC which can be measured by a typical ML given its length, frequency and magnitude resolution. The calculations were made for a temperature of $15^{\circ} \mathrm{C}$.

\begin{tabular}{lcll}
\hline $\begin{array}{l}\text { Magnitude } \\
\text { resolution }(\mathrm{dB})\end{array}$ & $\begin{array}{c}\text { Frequency } \\
(\mathrm{GHz})\end{array}$ & $\begin{array}{l}\text { Typical length } \\
\text { range }(\mathrm{km})\end{array}$ & $\begin{array}{l}\text { Threshold value } \\
\text { of } \mathrm{LWC}\left(\mathrm{grm}^{-3}\right)\end{array}$ \\
\hline 0.1 & 20 & $1-20$ & $0.42-0.02$ \\
1 & 20 & $1-20$ & $4.2-0.21$ \\
0.1 & 40 & $1-5$ & $0.11-0.02$ \\
1 & 40 & $1-5$ & $1.1-0.22$ \\
0.1 & 60 & $1-2$ & $0.05-0.03$ \\
1 & 60 & $1-2$ & $0.52-0.26$ \\
\hline
\end{tabular}

N. David et al.

Title Page

Abstract

Introduction

Conclusions

References

Tables

Figures

14

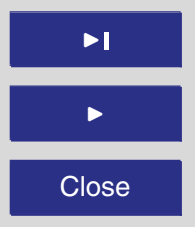

Back

Full Screen / Esc

Printer-friendly Version

Interactive Discussion 


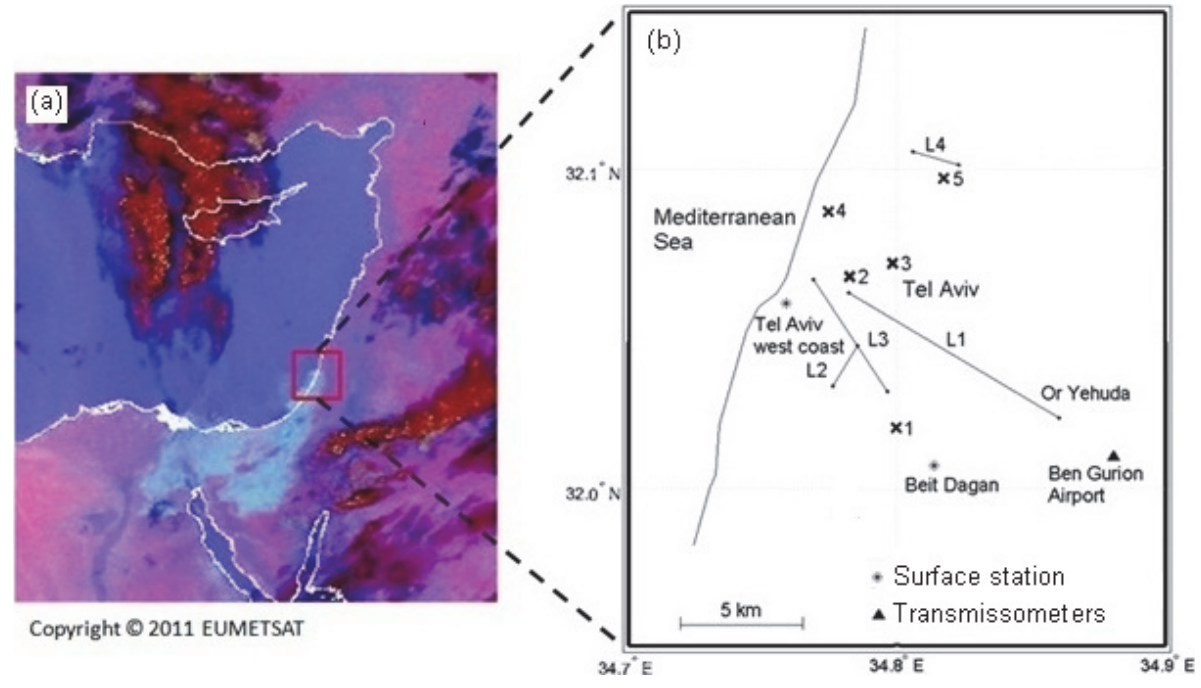

Fig. 1. The study area. (a) The image was taken by the Meteosat Second Generation (MSG) satellite on 16 November 2010, 02:00 h UTC. The fog is indicated in white covers the area of Sinai (Egypt) located south/southwest to the study area signified by the red-square, and continues along the western coast of Israel to the center of it. (b) The 20 MLs spread over nine physical paths. The longer $10 \mathrm{MLs}$ are spread over 4 physical paths of 1.7 to $8.5 \mathrm{~km}$ (marked as lines L4 to L1, respectively). The locations of the additional 10 short MLs (up to $400 \mathrm{~m}$, spread over 5 physical paths), are indicated by Xs. The links are found at heights of 7 to $31 \mathrm{~m}$ a.s.I. and are installed on towers at an altitude of between 7 and $60 \mathrm{~m}$ a.g.l. The Ben Gurion airport, where 3 transmissometers are located, is marked by the triangle. The two Israel Meteorological Service (IMS) surface stations are indicated by asterisks. The human observer is located at Beit Dagan station.
AMTD

5, 5725-5752, 2012

Novel method for fog monitoring using cellular networks infrastructures

N. David et al.

\section{Title Page}

\section{Abstract}

Conclusions

Tables

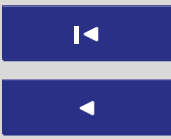

Back

\section{Introduction}

References

Figures

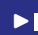

Close

\section{Full Screen / Esc}

Printer-friendly Version

Interactive Discussion 


\section{AMTD}

\section{$5,5725-5752,2012$}

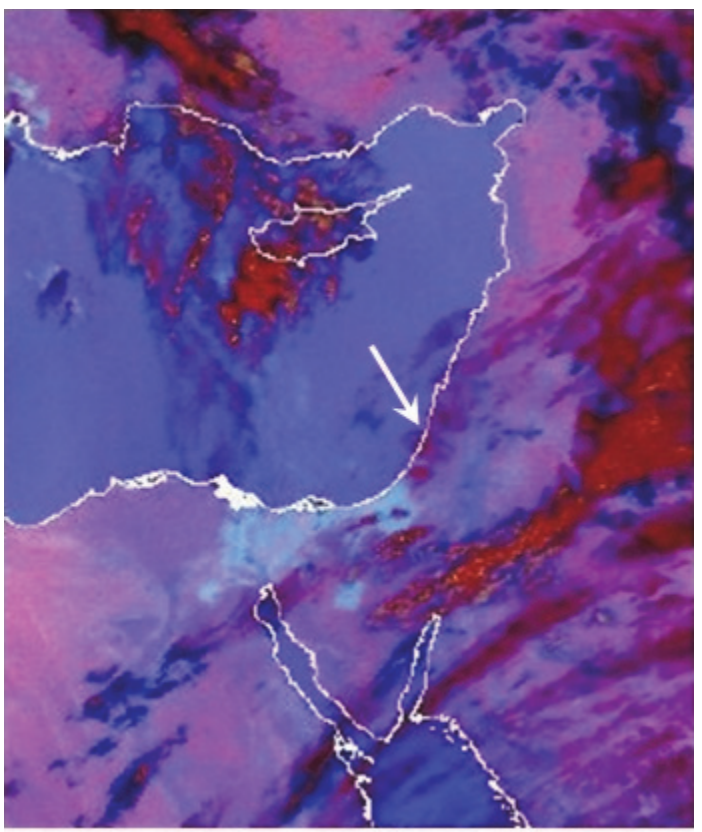

Copyright (C) 2011 EUMETSAT

Fig. 2. Satellite image (MSG). The image was taken at 22:00 UTC on the 15 November 2010. The middle and high level cloud cover, indicated in red colors (denoted by white arrow in the figure) partly obscure the fog.

\section{Novel method for fog monitoring using cellular networks infrastructures}

N. David et al.

\section{Title Page}

Abstract

Conclusions

Tables

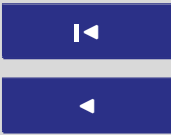

Back
References

Figures

Full Screen / Esc

Printer-friendly Version

Interactive Discussion 

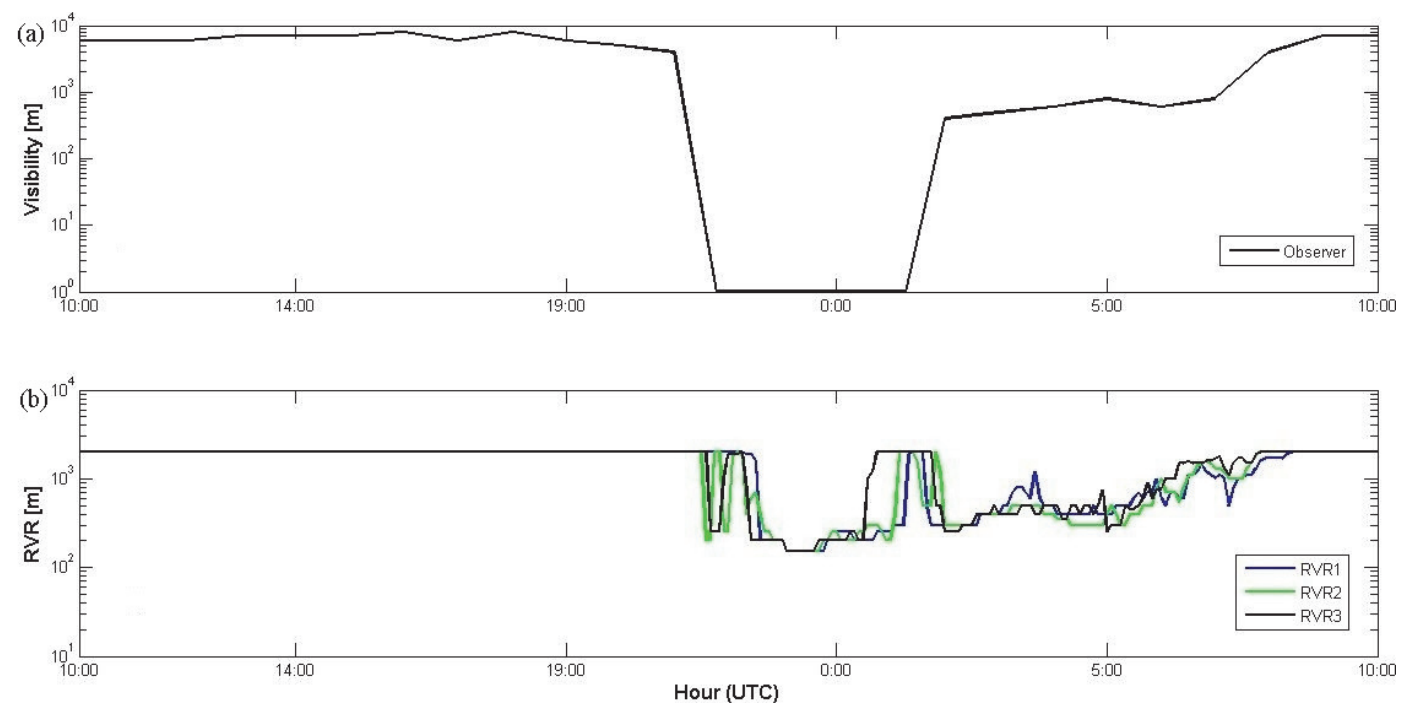

Fig. 3. Visibility and RVR measurements. The observations were taken between 15 November to 16 November 2010, between 10:00 to 10:00 UTC of the following day. (a) Visibility assessments as registered by the human observer at the Beit Dagan meteorological station found at an elevation of $31 \mathrm{~m}$ a.s.l. Observations were taken once an hour from a building at an altitude of about $10 \mathrm{~m}$ a.g.l. (It should be noted, though, that WMO regulations (WMO, 2008) require human visibility estimations to be performed from near-surface $(1.5 \mathrm{~m})$ level). (b) RVR measurements taken by the three transmissometers deployed at the airport over three different physical paths of lengths of $50 \mathrm{~m}$ each. All transmission and reception units are at an elevation of $2.5 \mathrm{~m}$ a.g.l., at $41 \mathrm{~m}$ a.s.l.
AMTD

$5,5725-5752,2012$

Novel method for fog monitoring using cellular networks infrastructures

N. David et al.

\section{Title Page}

\section{Abstract} Introduction

Conclusions

References

Tables

Figures

14

4

Back

lose

Full Screen / Esc

Printer-friendly Version

Interactive Discussion 


\section{AMTD}

$5,5725-5752,2012$

L1 (3.53 km)

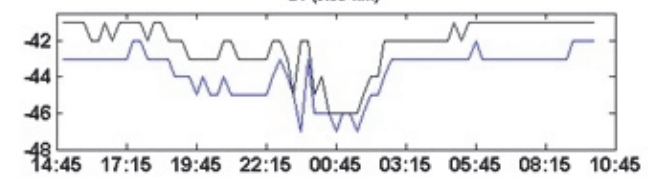

L3 $(4.67 \mathrm{~km})$

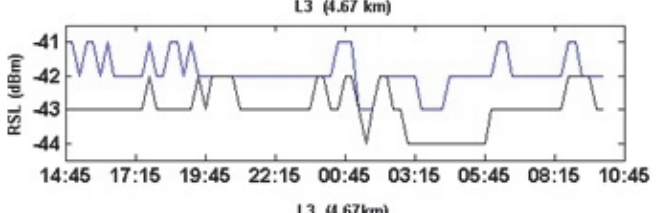

L3 $(1.67 \mathrm{~km})$

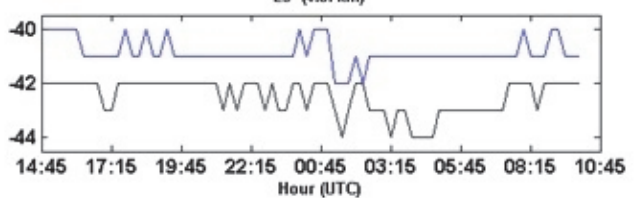

$14(1.66 \mathrm{~km})$

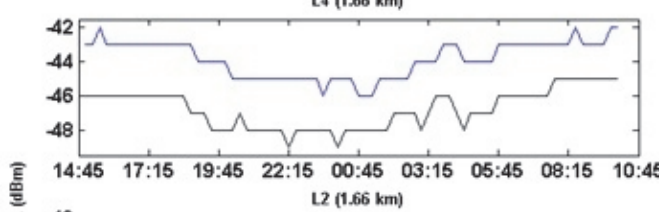

崖 $12(1.66 \mathrm{~km})$

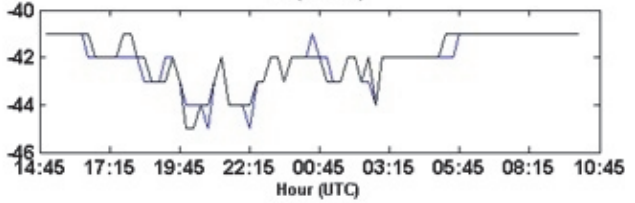

Fig. 4. MLs measurements. The maximum RSL measurements taken every $15 \mathrm{~min}$ by the 10 links installed at the study area along L1 to L4 propagation paths. Each of the two curves that appear on each graph describes the measurements of each of the two different links over the same physical path. The system's quantization error is $1 \mathrm{~dB}$ per each ML. The links located in the left column operate in the frequency range between $18-20 \mathrm{GHz}$, whereas those on the right column operate between $38-39 \mathrm{GHz}$. Increased attenuations, which were attributed to fog, can be seen in links L1, L2, L4 measurements between 18:45 to 05:30. The attenuations observed by the four MLs located over L3 path were ascribed to fog only between 01:30 to 01:45 when these were recorded at all L3 MLs during this time frame.

\section{Novel method for fog monitoring using cellular networks infrastructures}

N. David et al.

\section{Title Page}

Abstract Introduction

Conclusions

References

Tables

Figures

14

4

Back

lose

Full Screen / Esc

Printer-friendly Version

Interactive Discussion 


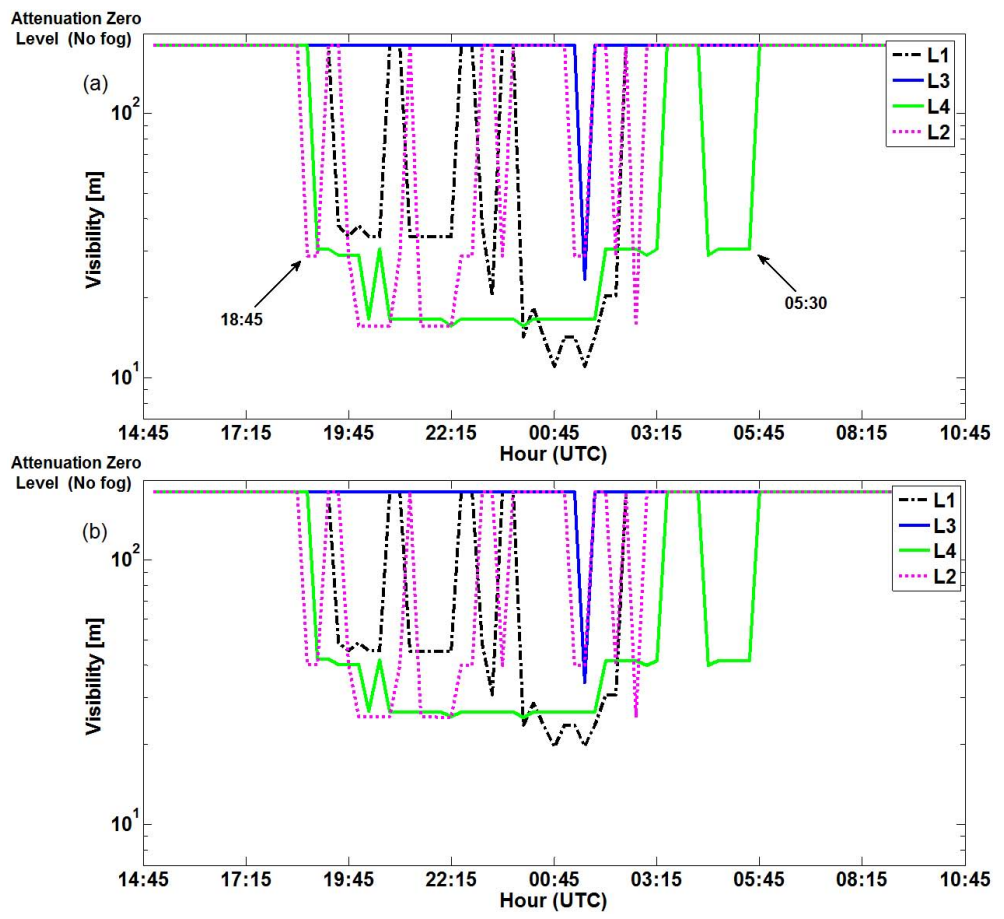

AMTD

5, 5725-5752, 2012

Novel method for fog monitoring using cellular networks infrastructures

N. David et al.

Title Page

Abstract

Introduction

Conclusions

References

Tables

Figures

Fig. 5. Visibility estimations. The measurements were acquired between 15:00 to 10:00 UTC of 15 to 16 November, respectively. Time intervals when the measured RSL did not cross the predefined zero level were defined as "non fog" periods. (a) Visibility estimations based on the MLs measurements as derived using the LWC-visibility relation of Kunkel (1984). The results range between 10 and $40 \mathrm{~m}$. The time interval when fog was measured using the novel technique is denoted by the arrows. (b) Visibility estimations based on the MLs measurements calculated using the formula derived by Gultepe et al. (2006). The results range between 20 to $50 \mathrm{~m}$.

\section{4}

4

\section{Back}

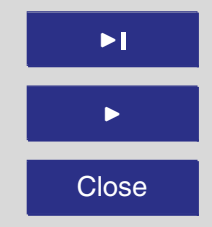

Full Screen / Esc

Printer-friendly Version

Interactive Discussion 